\title{
AS TEORIAS SOBRE ALFABETIZAÇÃO E OS IMPASSES EM TORNO DO CARÁTER SOCIAL DOS OBJETOS DE CONHECIMENTO
}

\author{
JúlIa AnACleto \\ Universidade de São Paulo (USP), São Paulo, São Paulo, Brasil
}

\begin{abstract}
Resumo: O artigo apresenta uma discussão em torno da questão do caráter social da linguagem escrita e do papel do outro na sua aprendizagem, a partir de revisão bibliográfica centrada em representantes das principais correntes de estudos sobre a alfabetização de crianças no Brasil. Apontando os limites que os estudos histórico-culturais de Ana Luiza Bustamante Smolka atribuem à perspectiva psicogenética, retomam-se os estudos de Emilia Ferreiro acerca do aspecto social implicado na alfabetização e sua importância para a discussão acerca dos determinantes estruturais da construção do conhecimento sobre a escrita. Por último, são apresentados alguns trabalhos no campo da aquisição da escrita que tomam a psicanálise lacaniana como referencial, destacando a inflexão do debate ao pensar a linguagem como lei estrutural do campo social.

Palavras-chave: Psicanálise e educação. Alfabetização. Escrita. Construção do conhecimento. Sujeito da linguagem.
\end{abstract}

As pesquisas coordenadas por Emilia Ferreiro acerca do processo de construção dos conhecimentos sobre a escrita pelas crianças fizeram história no meio educacional brasileiro, potencializando não apenas grandes alterações nas diretrizes educacionais como também a proliferação de pesquisas sobre o tema que partiam do referencial teórico da psicologia genética.

Assumindo como referencial a teoria piagetiana, a psicóloga argentina focou suas pesquisas na determinação da aquisição da escrita pelas leis da assimilação e da acomodação próprias ao processo cognitivo. A disseminação dessa perspectiva entre estudiosos e educadores brasileiros ensejou uma série de novos estudos que, sem recusar a importância do referencial piagetiano, apontavam limites e a necessidade de recorrer a outros referenciais, principalmente no sentido da consideração da questão da interação social e cultural no processo de aprendizagem.

O presente artigo parte dessa polêmica que, mesmo não sendo nova, continua a pautar boa parte dos debates em torno da aquisição da escrita (e da aprendizagem de forma geral), considerando de um lado os determinantes estruturais do processo cognitivo e por outro o papel das influências sociais, históricas e culturais nesse mesmo processo. Considerando os limites que Smolka (1988) aponta aos estudos 
psicogenéticos de Ferreiro no que diz respeito ao caráter social da aquisição da escrita, retoma-se os textos da psicóloga argentina onde essa se dedica à questão, trazendo importantes elementos para a problematização das noções de sujeito, objeto e representação.

Para além da retomada dos termos fundamentais do debate, o presente artigo aponta uma inflexão possível da discussão acerca do caráter social da escrita enquanto objeto de conhecimento, embasando-se em estudos que têm buscado estabelecer um paralelo entre aquisição da escrita e constituição do sujeito na perspectiva da psicanálise lacaniana. Isso porque considera-se que o campo dos estudos histórico-culturais, ao mesmo tempo em que faz avançar as reflexões sobre o caráter histórico e transitório das formas linguísticas, se distancia da problemática da construção do conhecimento como efeito de uma legalidade estrutural.

\section{ALFABETIZAÇÃO COMO PROCESSO CONSTRUTIVO: PAPEL ATIVO DO SUJEITO EPISTÊMICO}

Emília Ferreiro realizou seus estudos de doutorado no Centro de Epistemologia Genética de Genebra, na Suíça, nos primeiros anos da década de 1970, sob a orientação de Jean Piaget. Nesse período, dedicou-se a estudar, segundo a perspectiva psicogenética, certas aquisições conceituais no âmbito da língua oral, deparando-se já aí com a questão da transposição da teoria piagetiana para o campo dos conhecimentos linguísticos. Será a partir de seu retorno à Argentina que passará a se dedicar, em parceria com outras pesquisadoras, à intersecção entre a construção das estruturas lógicas de conhecimento e a aquisição da linguagem escrita.

A questão da alfabetização era assunto de primeira ordem no contexto latinoamericano e isso influiu nas suas escolhas (FERREIRO, 2001b). Havia, pois, uma pergunta em aberto acerca dos porquês dos altos índices de fracasso escolar das crianças no processo de alfabetização. A partir da formação de um grupo de colaboradoras, Emilia Ferreiro iniciou uma pesquisa em escolas públicas da região metropolitana de Buenos Aires, colocando em prática o que havia aprendido com Piaget.

A teoria piagetiana opera um deslocamento importante em relação à psicologia associacionista, pois sustenta que, entre os estímulos e a conduta, há a mediação do que denomina como "esquemas de assimilação do sujeito". Esses esquemas interpretam os estímulos, fazendo com que um mesmo estímulo possa gerar diferentes respostas dependendo dos esquemas de assimilação que o sujeito tenha à disposição. Segundo Ferreiro (2001a), Piaget interroga a criança, observa seu modo de agir sobre determinado objeto, seu modo de elaborar hipóteses sobre determinado problema, entendendo essas respostas como uma tentativa de organização lógica ou estruturação do real. Ou seja, uma tentativa de construção de um conhecimento, ao invés de repetição ou imitação de uma informação, que nada diz desse processo ativo de construção.

Partindo da premissa piagetiana de que o conhecimento é resultado de uma construção própria ao sujeito, Ferreiro e Teberosky (1989) voltam a atenção para as formulações infantis acerca da escrita anterior ao domínio do sistema alfabético, formulações essas que até então não tinham despertado interesse para as teorias sobre 
alfabetização. Suas pesquisas vão se direcionar para as possíveis indagações das crianças diante da escrita que têm a ver com a construção dessa enquanto objeto de conhecimento.

Ferreiro e Teberosky (1989) apresentam de forma detalhada os resultados de cada tipo de situação que foi apresentada às crianças e vão construindo um modelo evolutivo desse desenvolvimento cognitivo implicado na construção da escrita como um objeto de conhecimento. Apontam, pois, para os limites que definem em linhas gerais cada etapa e seus esquemas de assimilação, bem como os conflitos que as crianças são capazes de se apropriar e que engendram as reestruturações dos esquemas já constituídos. Dessa forma, Ferreiro reitera, a seu modo, que as mudanças dos esquemas de assimilação derivam de uma força interna ao sujeito, que é a de solucionar, da melhor maneira possível, os conflitos geradores de perturbações. Ou seja, a construção do conhecimento pelo sujeito não pode ser controlada a partir de um estímulo correto ou de uma informação fornecida no momento ideal. Antes, a questão é o que o sujeito é capaz de fazer com aquilo que o mundo externo supostamente the oferece como objetos de conhecimento.

\section{ALFABETIZAÇÃO COMO PROCESSO DISCURSIVO: A IMPORTÂNCIA DA INTERAÇÃO SOCIAL}

Logo que as pesquisas de Ferreiro e colaboradoras começam a ser divulgadas, com uma aceitação rápida e empolgante no meio educacional brasileiro, inicia-se um processo de apontamento de limites, principalmente no que tange ao deslocamento de sua teoria para o campo pedagógico. Dentre esses limites estaria o modo insuficiente como ela abordaria a questão da interação social e cultural no processo de aprendizagem.

Segundo Smolka (1988), Ferreiro, ao adotar o modelo piagetiano como principal referência teórica para analisar o processo de aquisição da escrita pelas crianças, estaria muito centrada na "construção individual do conhecimento", valorizando a similaridade em detrimento das diferenças de percursos das crianças em seu processo construtivo. Em seu trabalho de investigação acerca das elaborações das crianças sobre a escrita, ela relata que teria enfrentado certa dificuldade na análise dos dados somente a partir do referencial piagetiano. Isso porque as diferenças nas elaborações das crianças remetiam, para ela, às diferenças nas condições de interação "não apenas com a escrita, mas fundamentalmente com seus interlocutores" (SMOLKA, 1988, p. 19). Em outras palavras, as diferenças de contato com a escrita dependeriam de suas condições de vida e, mais especificamente, de suas condições de interação com adultos ou pessoas mais experientes que sejam interlocutores e informantes da criança.

Assim, Smolka (1988) irá buscar apoio teórico em correntes que Ihe possibilitem sustentar o que considera um "terceiro ponto de vista" sobre a alfabetização, distinto da perspectiva "tradicional" já criticada pelos estudos de Ferreiro; mas também distinta, em certos aspectos, desses últimos. Tratar-se-ia de tomar essas diferenças como aspectos fundamentais para o entendimento daquilo que está em jogo na aquisição da escrita, enquanto Ferreiro teria abordado a questão das diferenças como possível obstáculo a um processo que deve ser similar, posto que tributário de um programa evolutivo universal. 
Procurando se deter um pouco mais sobre a questão dessa influência "externa" no processo de aprendizagem da escrita, Smolka (1988) indaga acerca do caráter simbólico da escrita como objeto de conhecimento, buscando articular diferentes referenciais na consideração do que denomina o "aspecto discursivo" da aquisição da escrita. Por essa via, Smolka (1988) contribuiu com as bases de sustentação da perspectiva sócio-histórica de investigação acerca dos processos de aprendizagem em geral e da linguagem escrita em particular.

O foco da crítica ao modelo teórico piagetiano se dirige, em trabalhos como o de Smolka, a isso que se postula como universal e que rapidamente leva à conclusão de que só poderia ser da ordem do biológico. Em contraposição a isso, postulam que a construção do conhecimento deveria ser visto pelo ângulo de um processo social e, portanto, cultural e histórico.

Smolka (1988) parte dessa diferença que marcaria certa distância entre Piaget e Vygotsky - acerca do lugar da linguagem no desenvolvimento cognitivo - em sua tentativa de considerar a aquisição da escrita de modo distinto ao de Ferreiro. Sem pretender se opor ao construtivismo, sua elaboração vai no sentido de reconhecer o processo de aquisição da escrita como fruto de uma atividade mental composta por uma dimensão cognitiva e, ao mesmo tempo, uma dimensão discursiva.

Smolka (1988) assume uma concepção sociológica da linguagem, na qual essa estaria tomada no interior do campo social e subordinada a ele. Isso quer dizer que a linguagem se apresenta como parte integrante do social, entendido como conjunto de convenções historicamente determinadas e, portanto, sempre potencialmente modificáveis (ORLANDO, 1983).

Ao centrar suas análises na questão da interação social como fundamental no processo de aprendizagem da linguagem escrita, Smolka $(1988 ; 1993)$ se filia a correntes teóricas que salientam o campo social como campo histórico-social, ou seja, marcado por constantes transformações ligadas a condições concretas de vida. Mais ainda, a linguagem tomaria assento entre as práticas sociais e, portanto, estaria ela também subordinada sujeita a essa dinâmica de transformações históricas. Além disso, o que predomina é a consideração acerca do aspecto comunicativo da linguagem, conforme a própria Smolka afirma, juntamente com Góes: "Se a criança escreve enunciando seu pensamento para o outro, importa-nos examinar aquelas características que mais se relacionam à comunicabilidade do texto, à proposição dirigida a um leitor, destinatário não presente" (GÓES; SMOLKA, 1995, p. 58).

\section{FERREIRO: A REALIDADE SOCIAL DO OBJETO ESCRITA}

O caminho traçado por Smolka, e tantos outros que dedicam seus esforços de investigação no sentido de considerar o processo de aprendizagem da escrita no âmbito da perspectiva histórico-cultural, parte de inquietações quanto a uma suposta insuficiência do modelo piagetiano em dar conta do caráter essencialmente social que está em jogo na aquisição da linguagem escrita. No entanto, ao nos determos nesse debate, observamos como, de um lado, é possível encontrar na obra de Ferreiro (2001a) avanços quanto à consideração da influência da interação social no processo 
psicogenético dos conhecimentos e, de outro lado, como o campo dos estudos histórico-culturais, ao mesmo tempo em que faz avançar as reflexões sobre o caráter histórico e transitório das formas linguísticas, se distancia da problemática da impossibilidade de controle do processo construtivo do conhecimento, seja por parte do outro, seja por parte do próprio sujeito. Essa linha de estudos acerca dos processos de construção do conhecimento sobre a escrita acaba por deixar de lado o problema central que a perspectiva estruturalista em geral coloca e da qual Piaget participa à sua maneira ao postular que a construção do conhecimento está submetida a uma legalidade estrutural.

Retomando o percurso intelectual de Ferreiro (2001a), é importante acompanhar como ela se coloca o desafio de delimitar a escrita como um objeto de conhecimento. Ao se propor a aplicar a teoria piagetiana a um domínio não considerado pelo próprio autor, Ferreiro (2001a) se preocupa em não fazê-lo de um modo simplista, entendendo a aplicação em questão como o estabelecimento de uma nova relação entre um corpo teórico e um objeto de conhecimento, na qual ambos os lados saem modificados. Sendo a escrita um objeto de conhecimento bastante marcado pelas convenções sociais, se colocaria de forma mais aguda a questão do papel do outro no processo psicogenético de construção individual. Isso exigiria, segundo ela, uma exploração diversa, no sentido mesmo de fazer avançar a teorização no campo da psicogênese.

É importante, no âmbito dessa discussão, acompanhar o modo como a psicóloga argentina articula essa tensão entre os aspectos material e social do objeto. Um dos momentos em que a vemos avançar nessas reflexões é quando analisa de modo mais detido a relação entre oralidade e escrita (FERREIRO, 2003). Desde o início de seus estudos sobre a alfabetização, ela sustenta que não se deve pensar a escrita como uma transcrição da oralidade, propondo antes a ideia de que a escrita é um sistema de representação. Como tal, sua aquisição implicaria o desafio conceitual de delimitar quais propriedades daquilo que se pretende representar serão mantidas e quais serão excluídas (FERREIRO, 1986).

A autora vai ainda mais além ao afirmar que: “A aquisição da escrita não é a aquisição de uma técnica para transcrever a oralidade. É comprometer-se com outra retórica. É criar um novo objeto: a língua escrita" (FERREIRO, 2001a, p.53). Com isso, lança-se a uma desnaturalização tanto da relação entre oralidade e escrita, quanto da própria existência desses elementos, ao afirmar que nem uma nem outra são objetos "já dados", mas sim resultados de um "processo de objetivação". Propõe, com isso, uma outra forma de pensar a relação entre representante e representado.

É preciso desvincular-se de uma visão ontológica segundo a qual há 'coisas' (em sentido absoluto) e 'signos' (também em sentido absoluto). É muito mais adequada a noção piagetiana de sistemas hierárquicos que se constituem sobre a base de outros, em que as unidades de um nível não se transformam necessariamente nas unidades do outro nível. Realmente, as unidades redefinem-se em cada nível. Não se trata, então, de uma cadeia de símbolos que se substituem mutuamente (símbolos orais substituídos por símbolos escritos). Trata-se de outro nível de organização. Para a escrita, a linguagem é objeto em outro nível, e isto supõe que 
as unidades da escrita não estão predeterminadas pela fala, mas que devem ser redefinidas (FERREIRO, 2001a, p. 74).

Trata-se, pois, de sustentar a ideia de que esse real a ser representado não está dado de antemão, além de ser continuamente modificado pelas suas próprias representações. Ou seja, o que a autora sustenta é que os sistemas representativos não são neutros, mas, antes, possuem um poder instaurador de uma nova realidade conceitual.

A escrita é, pois, entendida como representação gráfica da linguagem com grande poder de influência sobre a própria definição de língua, pelo fato de exigir daquele que a utiliza um grau de reflexão metalinguístico que a oralidade não exigiria. Isso faz com que a autora ainda afirme que: "A realidade psicológica da língua é sua representação escrita" (FERREIRO, 2003, p. 154).

Podemos perceber o grau de complexidade que Ferreiro vai atribuindo à delimitação do que seja a linguagem escrita enquanto sistema de representação. De um lado, afirma que a escrita não representa a oralidade, sem contudo negar que haja relações de dependência entre elas; de outro lado, afirma que se trata de um sistema de representação, contudo que o objeto a ser representado tem sua realidade influenciada, senão instituída, pelo próprio processo de representação.

A autora ainda reforça a ideia de que a escrita não é naturalmente um objeto, mas é algo determinado socialmente, ao afirmar que a passagem da linguagem escrita de um objeto opaco a um objeto transparente para a criança equivale a uma passagem das marcas gráficas "daquilo que são" para aquilo que "não são" (FERREIRO, 2001a, p. 54). Essa passagem dependeria, segundo ela, da inserção da criança em uma comunidade letrada, visto que somente através de ações inter-individuais a escrita ganharia existência objetiva (FERREIRO, 1986).

O valor social dessas marcas gráficas não estaria contido nas suas características físicas, porém emergiria da intervenção do intérprete, dado seu caráter simbólico. Essa passagem seria um passo fundamental para que a criança possa vir a analisar essas marcas como parte de um sistema de representação com relações bem definidas com o sistema dos signos linguísticos. Daí a importância atribuída à leitura em voz alta endereçada à criança ainda não alfabetizada.

Ferreiro (2001a) aponta ser fundamental que o outro se comporte como intérprete, permitindo à criança participar de atos de leitura. A experiência proporcionada por alguém que lê em voz alta possibilita que a criança perceba essa possível relação entre a marca escrita e a fala. Ou seja, o ato de leitura em voz alta seria como um ato de iniciação para aquele que ainda não descobriu que as marcas gráficas têm relação com a linguagem.

O ato de leitura é um ato mágico. O que há por trás dessas marcas para que o olho leve a boca a produzir linguagem? Certamente, uma linguagem peculiar, muito diferente da comunicação face a face. Quem lê não olha o outro, mas a página (ou qualquer outra superfície sobre a qual se realizam as marcas). Quem lê parece falar para outro, mas o que diz não é sua própria palavra, mas a palavra de um 'Outro' 
que pode desdobrar-se em muitos 'Outros', saídos não se sabe de onde, escondidos também atrás das marcas (FERREIRO, 2001a, pp. 54-55).

Trata-se de uma experiência instauradora das particularidades da linguagem escrita propriamente dita. A partir dessa experiência "decisiva", as crianças passariam a indagar esse novo objeto, a fim de desvendar os mistérios desse ato mágico de leitura. Assim, ao enfatizar a importância da leitura como um ato fundamental no estabelecimento mesmo da realidade da escrita para a criança, Ferreiro (2001a) abre brechas para considerarmos a fala do outro endereçada à criança como constitutiva de uma realidade não física, mas social.

\section{AQUISIÇÃO DA ESCRITA E CONSTITUIÇÃO DO SUJEITO: SUJEIÇÃO ÀS LEIS ESTRUTURAIS DA LINGUAGEM}

Essas reflexões de Emilia Ferreiro em seu desafio de fazer avançar a teorização psicogenética mostram por quais caminhos ela avança na consideração da escrita enquanto objeto de conhecimento. Vemos como a questão da linguagem comparece na discussão da autora, na medida em que ela valoriza as experiências intersubjetivas como instauradoras do objeto para o sujeito. No entanto, podemos perceber como, ao falar do papel do intérprete, surge em sua elaboração, ainda que de modo sutil, a questão da sujeição do outro enquanto intérprete a algo que o transcende e que, coincidência ou não, Ferreiro (2001a) chama de "Outro", utilizando um termo muito caro à psicanálise lacaniana. Essa questão estará no cerne de alguns trabalhos de inspiração psicanalítica que se dedicam ao tema da alfabetização e que se relacionam justamente com um aspecto em comum entre as teorizações psicogenética e psicanalítica quanto à sujeição do pensamento a uma legalidade estrutural, ainda que essa seja pensada em sentidos diferentes em ambas as perspectivas teóricas.

Esses estudos apoiam-se num entrecruzamento entre os campos da Linguística e da Psicanálise para sustentar o argumento de que a aquisição da linguagem (tanto oral quanto escrita) é algo da ordem da entrada do sujeito no campo da linguagem e, portanto, da ordem da constituição enquanto tal de um sujeito do discurso, e não um processo que poderia ser apreendido como cognitivo, ou seja, como a construção de um objeto de conhecimento.

Sustentar a articulação entre aquisição da escrita e constituição do sujeito passa por um deslocamento em relação à perspectiva que toma o social em seu aspecto histórico-cultural. Do ponto de vista psicanalítico, não se trata de negar o estruturalismo em favor da historicidade, mas de afirmar o caráter estrutural do pensamento, no entanto sem afirmar isso como um dado biológico ou natural de qualquer tipo. Mais ainda, a linguagem é tomada não enquanto meio de interação social, mas como modelo estrutural do assim chamado campo social. Dessa maneira, ela passa a ser considerada mais em seu aspecto formal que comunicacional. Com isso opera-se uma inflexão no entendimento quanto ao papel do outro na aquisição da escrita pela criança: a emergência da escrita se apresentaria como decorrente de um movimento dialógico não intencional nem racional, posto que tanto a criança como o outro estariam tomados 
estruturalmente no campo das interpretações possíveis delimitadas pela própria ordem da linguagem.

Lemos (2002), em seus estudos acerca da aquisição da linguagem, aborda a heterogeneidade da fala da criança, apontando para a presença de fragmentos do enunciado precedente do adulto. Por isso, da mesma forma que Smolka (1988), seu primeiro passo foi considerar a aquisição da linguagem no interior de processos dialógicos, nos quais a unidade de análise passava a ser o diálogo e não o enunciado isolado da criança. No entanto, assumindo a perspectiva psicanalítica, Lemos (2002) passa a tratar a aquisição da linguagem como uma questão "propriamente linguística", na medida em que coloca a linguagem como mediadora da relação entre a criança e o outro. A aquisição da linguagem decorreria de movimentos interpretativos entre a criança e o adulto, sendo que a interpretação é aqui entendida como "efeitos da linguagem sobre a linguagem".

Pereira de Castro afirma que "o conceito de interpretação opõe-se ao de input" (PEREIRA DE CASTRO, 1998, p. 81). Segundo ela, nessa concepção de interpretação, não se deixa de lado o papel do adulto, mas não se trata de um papel de mediação ou de regulação da interação "entre a criança, a linguagem e o mundo" (PEREIRA DE CASTRO, 1998, p.85). A noção de interpretação apareceria aqui com o sentido de efeito - "efeito da fala do adulto na fala da criança, efeito da fala da criança na fala do adulto e efeito que a fala da criança promove no seu próprio processo de aquisição" (PEREIRA DE CASTRO, 1998, p. 82).

As formulações de Lemos (1998a) acerca da aquisição da linguagem partem, portanto, de uma constatação de que não se trataria de um processo cognitivo, mas propriamente linguístico, no qual opera, de forma preponderante, a relação com um outro, entendido não como provedor de informações sobre a língua ou interlocutor, mas enquanto "discurso ou instância de funcionamento da língua constituída" (LEMOS, 1998a, p. 161).

Lemos (1998a) nega-se a aceitar que a fala da criança em processo de aquisição seja marcada apenas pelas tentativas de regularização, o que conduziria à ideia de um trabalho cognitivo comandando o processo. No entanto, não nega que haja uma lógica subjacente a essa fala inicial. Tratar-se-ia de uma lógica própria à ordem da língua, marcada pelo jogo significante metafórico e metonímico. Dessa forma, distancia-se tanto das formulações de Ferreiro e Teberosky (1989), na qual o que é estruturante é da ordem da inteligência, quanto de Smolka (1988), que enfatiza o aspecto comunicacional da linguagem.

Apoiando-se na psicanálise lacaniana, a autora procura fazer avançar os estudos sobre aquisição da linguagem, enfatizando principalmente o modo como Lacan irá tomar as formulações do campo da linguística estrutural em sua tentativa de estabelecer uma "teoria da determinação do sujeito pelo significante" (ROUDINESCO; PLON, 1998, p. 709). Segundo Dor (1992): "A supremacia do significante se traduz, portanto, eletivamente, por uma dominação do sujeito pelo significante, que o predetermina lá mesmo onde ele crê escapar a toda determinação de uma linguagem que ele pensa controlar" (DOR, 1992, p. 45). 
O aforismo "o significante representa o sujeito para outro significante" ganha sua força na medida em que Lacan sustenta, diferentemente do que havia feito Saussure, que o significante possui autonomia em relação ao significado, o que implica dizer que ele está estruturalmente tomado num deslizamento constante da significação. Assim, a união entre significante e significado é instável e o sujeito do inconsciente opera nesse hiato, nessa abertura que se faz entre uma e outra significação. $O$ sujeito seria, então, a expressão mesma dessa instabilidade, revelando-se nesse querer dizer outra coisa que aquilo que se pensa querer dizer.

Lacan recorrerá à definição de Jakobson, de que um discurso se constrói sobre os eixos metafórico e metonímico, para tentar estruturar o modo como se estabelece sua relação com o significado. Segundo Roudinesco e Plon (1998), isso o permitiu "conferir um estatuto lógico à teoria do significante" (p. 709).

Recorrendo a essa teorização, Lemos (1988a) afirma que o adulto parte de uma suposição, qual seja, a de que aquilo que a criança the oferece como uma "imagem acústica" seja tomado como significante, ou seja, passível de interpretação, de significação, por meio de processos metafóricos e metonímicos, isto é, pela via da semelhança e da diferenciação, os quais darão àquele significante um sentido antecipado, uma identificação enquanto unidade. A criança, por sua vez, tomará de volta esse significante tornado unidade virtual pela interpretação adulta, colocando-o em novas relações de significação, ou seja, ressignificando-o.

Lemos (2002) afirma que essas modificações apontam para mudanças de posição em uma estrutura. Em cada uma das posições predominaria um tipo de efeito da relação de interpretação em que os sujeitos encontram-se inscritos, tendo como resultado o deslocamento da criança "da posição de interpretado" para a posição "de intérprete de si mesmo e do outro" (LEMOS, 1998a, p. 167).

Ao tratar propriamente da aquisição da escrita, Lemos (1998b), parecido com o que vimos em Ferreiro, fala em transformação das marcas gráficas em algo "visível", remetendo-nos à "indagação sobre como algo se torna outro ou passa a se apresentar como outro à percepção e à interpretação, transformando assim o sujeito em alguém que 'lê', isto é, que vê o que não estava lá" (LEMOS, 1998b, p. 18). Além disso, também como Ferreiro (2001a), aponta para a importância da mediação por meio de atos de leitura para que o sujeito passe a ver isso que não via e que não estava lá como materialidade física.

No entanto, diferentemente do que aparece em Ferreiro (2001a), esse processo não constituiria a linguagem escrita em objeto de conhecimento capaz de ser apropriado e reconstruído pelo sujeito. Antes, tratar-se-ia de tornar a escrita "significante para um sujeito" (LEMOS, 1998b, p.19), sendo o significante aquele capaz de representar o sujeito para outro significante e, ao mesmo tempo, articular um resto (desejo). Assim, a visibilidade em questão seria algo da ordem da significância, ou seja, de tornar as marcas gráficas algo passível de ser significado, permitindo ao sujeito articular-se na linguagem.

\section{ALFABETIZAÇÃO COMO PROCESSO SIGNIFICANTE}

Voltadas muito mais ao processo de aquisição da linguagem oral, as formulações de Lemos passam a servir de norteamento para o trabalho de Borges (2006) 
acerca da aquisição da escrita, pois oferecem um contraponto às teorias sobre alfabetização ancoradas na psicologia cognitivista, nas quais o desenvolvimento linguístico é explicado a partir de aspectos do desenvolvimento cognitivo e/ou comunicativo/social.

Segundo essa autora, as teorias sobre a alfabetização pressupõem que o sujeito é usuário da escrita, ou seja, a escrita é um instrumento que ele utiliza para atingir um certo objetivo comunicativo. Desse ponto de vista, a criança é colocada diante da escrita no contexto, é chamada a usá-la e, dessa forma, vai descobrindo as leis de funcionamento da linguagem, ou seja, caminhando em direção ao controle dessa.

Essa perspectiva, no entanto, não abriria espaço para a escrita inicial e seu caráter enigmático, já que seriam vistas como indeterminadas do ponto de vista da apreensão cognitiva e também das intenções comunicativas. A possibilidade de que essas manifestações escritas fossem tomadas como enigmas que demandam interpretação teria decorrido do reconhecimento de que, para além da indeterminação, há ali a "presença do Outro", o que levou a autora a um "modo novo de olhar para estas produções, bem como para o processo de alfabetização" (BORGES, 2006, p. 44). Isso porque, assumindo a noção de especularidade de Lemos, as peculiaridades da escrita inicial passam a ser vistas como marcas da entrada singular do sujeito na linguagem.

A articulação da aquisição da escrita com a constituição do sujeito, do ponto de vista da determinação de ambos os processos por uma legalidade estrutural própria à linguagem, retorna à problemática cara aos estudos de Ferreiro acerca da escrita enquanto sistema de representação. Isso porque o questionamento do objeto enquanto entidade palpável e definida a priori por uma suposta essência desemboca na problematização da relação sujeito-objeto como uma relação de representação do segundo pelo primeiro.

Como vimos, Ferreiro (2001a) chega ao ponto de definir a representação enquanto a instauração de uma realidade conceitual, desvinculando-a da ideia de referente de uma realidade material naturalmente dada. Assumindo o referencial da psicanálise, Borges (2006) avança na problematização da noção de representação conforme apreendida pela Psicologia, afirmando que em Freud a percepção ganharia estatuto de representação, sendo negada a ideia de "impressão sensível". Não haveria, pois, percepção que não fosse já uma representação, ou seja, não há imagem ou conceito que não seja um fenômeno psíquico complexo. A noção freudiana de representação inconsciente se aproximaria, nessa leitura, de uma inscrição psíquica em forma de traço, remetendo à noção linguística de significante. Portanto, a noção de traço presente na obra freudiana desde muito cedo apontaria para um "desprendimento das categorias de ser, de essência, de substância" (BORGES, 2006, p. 105).

Essa primazia da linguagem na construção de qualquer representação e, portanto, na estruturação do psiquismo está relacionada à nomeação, pois seria apenas através dela que o objeto poderia apresentar certa consistência, uma aparência que será captada pela percepção. A partir dessa radical negação de objetos que não sejam desde sempre signos, a representação passa a ser vista como algo da ordem da instituição de uma realidade, a realidade simbólica, única que o ser humano, ser de linguagem, seria capaz de habitar. 
Borges (2006) vai apontar para a presença, na escrita inicial das crianças, de elementos que advêm dos textos com os quais estão em contato, encadeados de tal forma que não têm efeito de sentido. Trata-se de um processo de recorte e colagem desses fragmentos ou unidades. Submetidas a um movimento interpretativo, essas escritas engendrariam um processo de significação, segundo o qual as unidades não convencionais que aparecem ali ganham estatuto de unidades diferenciadas, a partir do momento em que, colocadas em relação a outros textos, emergem delas semelhanças e diferenças. Dessa forma, assumem uma posição estrutural, mesmo que ainda não sejam posições estabilizadas, pois distantes daquelas do discurso social.

Conforme aponta a análise da autora, trata-se de entender essas escritas ditas iniciais, heterogêneas e indeterminadas, incapazes de serem interpretadas nos marcos da tentativa de regularização e formalização da escrita enquanto objeto de conhecimento, como obedecendo já a uma ordem, não aquela da lógica formal, mas a da linguagem, cujas leis de funcionamento são as da metáfora e metonímia. Com esse estudo, Borges (2006) buscou sustentar o argumento - como Lemos (1998a; 2002) fez com relação à oralidade - de que a aquisição da escrita não seria resultado de um trabalho cognitivo, mas dos movimentos linguísticos que fundam o próprio sujeito enquanto um ser de linguagem. Isso porque o sujeito está capturado pela estrutura ao invés de tomá-la como objeto de conhecimento ou meio de interlocução.

\section{CONSIDERAÇÕES FINAIS}

Tendo percorrido certo caminho conceitual em torno dos determinantes da aquisição da escrita pela criança, buscamos circunscrever um aspecto fundamental do debate entre as correntes de teorização sobre o processo de alfabetização, predominantes no Brasil. Trata-se da questão acerca do papel do outro na construção da escrita pela criança, a qual divide as opiniões dos pesquisadores. Apesar dos limites apontados pelos estudos histórico-culturais de Smolka à perspectiva psicogenética, buscamos retomar os trabalhos de Emilia Ferreiro acerca do aspecto social implicado na alfabetização, dando ênfase a escritos menos difundidos de sua pesquisa, a fim de retomar a discussão acerca dos determinantes estruturais da construção do conhecimento sobre a escrita. Em seguida, apresentamos o modo como o referencial psicanalítico pode servir de guia para o avanço dessa discussão, na medida em que afirma a importância da intersubjetividade no posicionamento da criança na linguagem escrita, sem, contudo, perder de vista que esse processo é regido pelas leis estruturais da linguagem, que fundam mesmo a existência de um sujeito, entendido como sujeito de linguagem.

Ao abordar a articulação da escrita com a constituição subjetiva, aponta-se para outra concepção de sujeito, de objeto, bem como de representação, estando todas inter-relacionadas. Isso possibilita um avanço na problematização da distinção entre realidade e representação. Recorrendo a trabalhos que sustentam que a aquisição da escrita, assim como a aquisição da oralidade, não passa pela sua transformação em objeto de conhecimento, mas, antes, responde à lógica mesma da estruturação do sujeito no campo da linguagem (BORGES, 2006; LEMOS, 2002), procuramos avançar na 
discussão acerca dos determinantes do processo de alfabetização, a partir da articulação entre constituição subjetiva e aquisição da escrita.

Artigo recebido em: $20 / 12 / 2017$

Aprovado para publicação em: 18/02/2018

\section{THEORIES ON LITERACY AND THE IMPASSES AROUND THE SOCIAL CHARACTER OF KNOWLEDGE OBJECTS}

ABSTRACT: The paper presents a discussion over the question of the social character of written language and the role of the other within literacy. Such discussion is made from a bibliographical review centered on the main trends of child literacy studies in Brazil. Indicating the limits attributed to the psychogenetic perspective by Ana Luiza Bustamante Smolka's historical-cultural studies, we return to Emilia Ferreiro's works on the social aspect implicated in literacy and its importance to the discussion over the structural determinants of knowledge building on writing. Finally, we present a few works on the written language acquisition field which grasp Lacanian psychoanalysis referential, highlighting the inflexion given to the debate while regarding language as a structural law of the social field.

KEYWORDS: Psychoanalysis and education. Literacy. Written language. Knowledge building. Subject of language.

\section{LAS TEORÍAS ACERCA DE LA ALFABETIZACIÓN Y LOS IMPASES ALREDEDOR DEL CARÁTER SOCIAL DE LOS OBJETOS DEL CONOCIMIENTO}

RESUMEN: El artículo presenta una discusión acerca de la cuestión del carácter social del lenguaje escrito y del papel del otro en su aprendizaje a partir de una revisión bibliográfica centrada en representantes de las principales corrientes de estudios sobre la alfabetización de niños en Brasil. Indicando los límites que a la perspectiva psicogenética les atribuyen los estudios históricoculturales de Ana Luiza Bustamante Smolka, son aquí retomadas las pesquisas de Emilia Ferreiro acerca del aspecto social implicado en la alfabetización y su importancia para la discusión acerca de los determinantes estructurales de la construcción de conocimiento sobre la escrita. Por último, son presentados algunos trabajos en el campo de la adquisición de la escrita que toman la psicoanálisis de Lacan como referencial, destacando la inflexión del debate al pensar el lenguaje como ley estructural del campo social.

PALABRAS CLAVE: Psicoanálisis y educación. Alfabetización. Escrita. Construcción del conocimiento. Sujeto del lenguaje. 


\section{REFERÊNCIAS}

BORGES, S. O quebra-cabeça: a alfabetização depois de Lacan. Goiânia: Ed. da UCG, 2006.

DOR, J. Introdução à leitura de Lacan. Porto Alegre: Artes Médicas, 1992.

FERREIRO, E. Reflexões sobre alfabetização. São Paulo: Cortez, 1986.

FERREIRO, E. Atualidade de Jean Piaget. Porto Alegre: Artmed, 2001a.

FERREIRO, E. Cultura escrita e educação. Porto Alegre: Artmed, $2001 \mathrm{~b}$.

FERREIRO, E. Escrita e oralidade: unidades, níveis de análise e consciência metalinguística. In: FERREIRO, E. Relações de (in)dependência entre oralidade e escrita. Porto Alegre: Artmed, 2003.

FERREIRO, E.; TEBEROSKY, A. Psicogênese da língua escrita. Porto Alegre: Artmed, 1989.

LEMOS, C. T. G. de. Das vicissitudes da fala da criança e de sua investigação. Cadernos de Estudos da Linguagem, 42, 41-69, Jan./Jun., 2002.

LEMOS, C. T. G. de. Os processos metafóricos e metonímicos como mecanismos de mudança. Substratum: temas fundamentais em psicologia e educação, 1(3), 151-172, 1998 .

LEMOS, C. T. G. de. Sobre aquisição da escrita: algumas questões. In: ROJO, R. Alfabetização e Letramento: perspectivas linguísticas. Campinas: Mercado de Letras, $1998 b$.

ORLANDI, E. A linguagem e seu funcionamento. São Paulo: Brasiliense, 1983.

PEREIRA DE CASTRO, M. F. Sobre a interpretação e os efeitos da fala da criança. Letras de Hoje, 33(2), 81-87, junho/ 1998.

ROUDINESCO, E.; PLON, M. Dicionário de Psicanálise. Rio de Janeiro: Jorge Zahar Ed., 1998.

SMOLKA, A. L. B. A dinâmica discursiva no ato de escrever: relações oralidade-escritura. In: SMOLKA, A. L. B.; GÓES, M. C. R. de. A linguagem e o outro no espaço escolar: Vygotsky e a construção do conhecimento. Campinas: Papirus, 1993.

SMOLKA, A. L. B. A criança na fase inicial da escrita - a alfabetização como processo discursivo. Campinas: Cortez, 1988. 
SMOLKA, A. L. B; GÓES, M. C. R. de. A criança e a linguagem escrita: considerações sobre a produção de textos. In: E. S. ALENCAR (Org.). Novas contribuições da psicologia aos processos de ensino e aprendizagem. São Paulo: Cortez, 1995.

SOARES, M. Linguagem e escola: uma perspectiva social. São Paulo: Ática, 1997.

JúlIA ANACLETO: Mestre em Educação, desenvolve, atualmente, pesquisa de doutorado na linha de pesquisa de Psicanálise e Educação no Programa de Pós-graduação da Faculdade de Educação da USP. Tem como temas de interesse, na interface entre psicanálise e educação, os debates acerca da construção de conhecimento pela criança, aquisição da escrita e processos de subjetivação. É membro do Laboratório de Estudos e Pesquisas Psicanalíticas e Educacionais sobre a Infância (LEPSI).

E-mail: julia.anacleto80@gmail.com 